\title{
Controlled release formulation of oxycodone in patients with moderate to severe chronic osteoarthritis: a critical review of the literature
}

This article was published in the following Dove Press journal: Journal of Pain Research

21 April 2012

Number of times this article has been viewed

\author{
Robert Taylor Jr' \\ Robert B Raffa ${ }^{2}$ \\ Joseph V Pergolizzi Jr $r^{3-5}$ \\ 'NEMA Research Inc, Naples, FL; \\ ${ }^{2}$ Department of Pharmaceutical \\ Sciences, Temple University School \\ of Pharmacy, Philadelphia, PA \\ ${ }^{3}$ Department of Pharmacology, \\ Temple University School of Medicine, \\ Philadelphia, PA ${ }^{4}$ Department of \\ Medicine, Johns Hopkins University \\ School of Medicine, Baltimore, MD; \\ ${ }^{5}$ Department of Anesthesiology, \\ Georgetown University School of \\ Medicine, Washington, DC, USA
}

Correspondence: Robert Taylor Jr NEMA Research Inc, 840 I I I th Avenue North, Suite 9, Naples, FL 34I08, USA Tel +l 2395973662

Email robert.taylor.phd@gmail.com

\begin{abstract}
Osteoarthritis (OA) is a physically and emotionally debilitating disease that predominantly affects the aging adult population. Current pharmacologic treatment options primarily consist of nonsteroidal anti-inflammatory drugs and/or acetaminophen, but associated side effects, analgesic limitations, especially in the elderly, and the need for around-the-clock analgesia have led physicians to search for alternative analgesics. Opioids have shown effectiveness at mitigating both chronic cancer and noncancer pain, and their ability to be placed into controlled release (CR) formulations suggests that they may prove efficacious for OA patients. One formulation, oxycodone $\mathrm{CR}$, has shown effectiveness in cancer pain patients and in some trials of noncancer low back pain. In this review, the objective was to synthesize the reported findings by researchers in this field and present an up-to-date look at the efficacy, safety, and tolerability of oxycodone CR in OA patients. Public literature databases were searched using specific keywords (eg, oxycodone CR) for studies assessing the efficacy and safety profile of oxycodone CR and its use in patients with OA. A total of eleven articles that matched the criteria were identified, which included three placebo-controlled trials, six comparative trials, one pharmacokinetic study in the elderly, and one long-term safety trial. Analysis of the studies revealed that oxycodone $\mathrm{CR}$ is reasonably efficacious, safe, and tolerable when used to manage moderate to severe chronic OA pain, with similar side effects to that of other opioids.
\end{abstract}

Keywords: oxycodone, extended release, controlled release, opioid, osteoarthritis

\section{Introduction}

Osteoarthritis is a common joint disorder among the older adult population..$^{1,2}$ One in four adults over the age of 65 worldwide are affected by this disease, ${ }^{3}$ and the prevalence has been reported to be $27.2 \%, 13.8 \%$, and $27.0 \%$ in hands, knees, and hips, respectively. ${ }^{4,5}$ It is a disease that ultimately leads to destruction of the cartilage and the bone in the joints, ${ }^{6}$ and can be a result of a number of factors besides age including genetics, gender, race, weight, and diet. ${ }^{7}$ Severe chronic pain is known to be associated with the disease and contributes substantially to a patient's disability, ${ }^{8}$ in addition to having a negative impact on motor function, sleep, mood, and overall quality of life. ${ }^{9}$ Thus, a major goal of therapy has been for the control of pain. ${ }^{10}$

Osteoarthritis is comprised of a complex collection of pathophysiological processes that both individually and in combination give rise to a multifaceted variety of pain types. It includes damage and degradation of several joint structures and tissue types, such as cartilage (reduced proteoglycan content), smooth muscle, and bone. In addition, new bone outgrowths at the margins of the injury further irritate the surrounding areas (eg, a joint capsule) and recruit a cascade of more inflammatory responses. The multifactorial 
combination of mechanical and biochemical insults together with inflammation lead to a pain of multifaceted etiology and type. Treatment of such a complex pain is unlikely to be successful using an analgesic regimen that relies only on one analgesic class approach. Thus, opioids, both from a mechanistic and efficacy point of view, with adequate precautions are a rational pharmacologic option for the appropriate patient and situation.

Current treatment options for reducing pain combine pharmacologic and nonpharmacologic approaches. Nonpharmacologic approaches may consist of physical and occupational therapy in addition to increasing patient awareness and education. ${ }^{11}$ Pharmacologic approaches usually consist of analgesic therapy. Initial analgesic therapy may consist of acetaminophen, salicylates, nonsteroidal anti-inflammatory drugs, or weak opioids (eg, propoxyphene) and mixed-acting analgesics (eg, tramadol). ${ }^{11-14}$ Use of these analgesics, especially acetaminophen and nonsteroidal anti-inflammatory drugs, have limitations and have been shown to be mildly effective to noneffective in some studies. ${ }^{15-18}$ Some of these limitations include an analgesic ceiling effect and any increase of dosage can lead to a number of side effects including hepatotoxicity, renal toxicity, cardiovascular effects, and gastrointestinal effects. ${ }^{19-25}$

Such limitations have led some physicians to examine alternative analgesics for osteoarthritis. Opioids have demonstrated their effectiveness in mitigating pain related to both chronic cancer and noncancer pain and thus have recently been viewed as a viable alternative. Several reviews summarize the appropriateness, efficacy, and safety of opioid use for treatment of the pain associated with osteoarthritis. For example, McHughes and Lipman discuss opioids as an option for OA pain when other interventions are insufficient ${ }^{26}$ and Howes et al included a Cochrane systematic review of studies that involved trials in which patients received placebo or oral codeine, morphine, oxycodone, or oxymorphone. ${ }^{27}$ Both reviews concluded that the evidence from such trials supports the use of opioids as part of a comprehensive approach in the management of osteoarthritis pain.

Immediate release forms of various opioids have demonstrated efficacy and safety for use for some chronic pain conditions $;{ }^{28}$ however, it has been recommended that for chronic continuous pain, opioids should be administered around-theclock in order to provide consistent pain relief. ${ }^{29}$ This can pose a challenge for the use of immediate release formulations as this requires a patient to frequently administer their medication in order to prevent any breaks in pain relief. To circumvent this problem and other problems associated with immediate release formulations, extended release (ER)/controlled release (CR) formulations of some opioids have been marketed. Advantages of ER opioids may include:

- Provides sustained analgesia for 12-24 hours, thus no gaps in pain relief; ${ }^{30,31}$

- Provides consistent plasma concentrations; ${ }^{32}$

- Eliminates need to wait for pain to return before taking next dose; 33

- May help with better nighttime pain control; ${ }^{33}$

- May help increase compliance;

- Less "clock-watching"

Several oral analgesics are available in ER formulations and these include oxymorphone ER, oxycodone CR, morphine ER, tramadol ER, fentanyl transdermal, and buprenorphine transdermal. Oxycodone CR is a twice-daily (every 12 hours) formulation that has been reported to be effective in the management of cancer pain ${ }^{34-38}$ and chronic noncancer pain. ${ }^{39,40}$ Its use in osteoarthritis has been tested in both placebo-controlled and comparative studies, and a summary and evaluation of those studies is the focus of this review.

Because the management of pain for patients who have moderate to severe chronic pain related to osteoarthritis requires around-the-clock analgesia, it is reasonable to postulate that ER or CR formulations might provide patients with not only a simpler dosing schedule, but also a more consistent and enduring relief from pain. It was the objective of this review to evaluate this for an opioid that had sufficient available literature. Oxycodone CR formulation provided such an opportunity.

\section{Methods}

\section{Literature search strategy}

The strategy for the identification of studies included the electronic searching of the PubMed/MEDLINE database, EMBASE, and The Cochrane Library from database inception to December 2011. Search terms that were used included: "osteoarthritis," "oxycodone," "CR" [controlled release], "ER" [extended release]. Terms were selected based on the main terms in the title of the review. Terms were not used individually, but in combination in order to achieve a highly condensed and focused result list. Combinations included: "osteoarthritis AND oxycodone," "osteoarthritis AND oxycodone AND CR," "osteoarthritis AND oxycodone AND ER," "oxycodone AND CR," “oxycodone AND ER."

\section{Selection criteria}

The identified citations were then further limited to any clinical study or review article describing the safety, efficacy, 
and/or tolerability of oxycodone CR for osteoarthritis. Studies that analyzed other chronic pain conditions in conjugation with osteoarthritis were also included. Studies exclusively describing only immediate release forms of oxycodone were not included. The initial literature search was performed by author RT and all articles were analyzed by all of the authors. To identify potential articles missed by the electronic search, the bibliographies of the electronically identified articles were analyzed and any appropriate article based on the title and abstract were retrieved.

\section{Assessment of methodological quality}

The quality of the articles extracted was not assessed. The goal was to present published studies regardless of the design type and quality. The intention was to present to the reader all research conducted on the current topic.

\section{Data extraction and analysis}

Data extracted from the studies included pain intensities, quality of life assessments, and adverse events (AEs). No formal statistical or meta-analysis was conducted on the studies and this task was beyond the scope of this review.

\section{Results}

\section{Literature search}

In the literature search, a total of eleven articles were identified that reviewed the safety, efficacy, and/or tolerability of oxycodone CR and its use in patients with osteoarthritis. All eleven studies were reviewed and included in this review. The studies included three placebo-controlled trials, six comparative trials, one pharmacokinetic study in the elderly, and one long-term safety trial. The comparative studies looked at oxycodone versus either oxymorphone, hydromorphone, or tapentadol.

\section{Placebo-controlled trials of CR formulation of oxycodone}

\section{Pain intensity}

In a trial of 167 patients with moderate to severe chronic osteoarthritis pain, oxycodone CR formulation was compared to placebo for up to 30 days. ${ }^{41}$ After a titration period using immediate release oxycodone, patients' pain intensity decreased from 2.44 to $1.48(P=0.0001)$ on a four-point scale and was significantly superior to the placebo $(P \leq 0.05)$. In another trial of 133 patients using oxycodone CR (OxyContin ${ }^{\circledR}$ ), daily mean pain intensity was significantly $(P<0.05)$ reduced at week one and week two assessment with $20 \mathrm{mg}$ every 12 hours taken every day when compared to placebo. There was no difference in pain intensity throughout the day and evening, indicating a stable, continuous relief from pain. In addition, a $20 \%$ reduction in pain was achieved within 1 day of taking $20 \mathrm{mg}$ every 12 hours and 2 days of taking $10 \mathrm{mg}$ every 12 hours. ${ }^{42}$ When the trial was extended up to 72 weeks, pain intensity remained below a moderate level (less than two on a four-point scale) throughout the study. In another study conducted by Markenson et al using oxycodone CR (OxyContin) average pain intensity as measured by a ten-point Brief Pain Inventory scale was significantly reduced in the oxycodone group versus placebo (5.1 versus $6.0 ; P=0.022)$ at visit two and (4.9 versus $6.0 ; P=0.024$ ) at 90 days, with approximately $38 \%$ of the patients achieving a $30 \%$ reduction in pain at the end of 90 days. ${ }^{43}$ Other Brief Pain Inventory assessments for pain including pain "right now," "worst pain," "least pain," and "pain relief" were all improved from baseline values and were significantly superior to placebo. In addition, Western Ontario and McMaster University Osteoarthritis Index scores at 30 and 60 days of treatment were significantly reduced for pain $(-13.0$ and -17.8 versus -4.1 and -2.4$)$, stiffness $(-15.8$ and -21.7 versus 0.3 and 0.1$)$, and physical function $(-12.4$ and -17.1 versus -3.2 and -3.8$)$ in patients taking oxycodone CR versus placebo, respectively. ${ }^{43}$ Overall, pain intensity was significantly reduced in the oxycodone CR group versus placebo in all three trials indicating oxycodone CR's effectiveness in mitigating pain in osteoarthritis.

\section{Quality of life assessments}

In a study by Caldwell et al, sleep quality was compared in patients receiving oxycodone $\mathrm{CR}$ versus placebo. ${ }^{41}$ Sleep scores improved from 2.58 to 3.57 on a five-point scale $(P=0.0001)$ and was significantly superior to placebo $(P \leq 0.05)$. In a trial of 133 patients, use of $20 \mathrm{mg}$ every 12 hours oxycodone CR for up to 2 weeks significantly improved a patient's mood, sleep, and enjoyment of life, in addition to improving the patients' walking ability, general activity, normal work, and their relations with others. Daily activities were able to be performed with minimal to no difficulty and the patients' performance were not impaired due to oxycodone CR. ${ }^{42}$ When the trial was extended up to 72 weeks, daily activities were unaffected to moderately affected by pain and their sleep was considered "fair to good," with the number of awakenings reduced by approximately $50 \%$ after 6 months (1.7 versus 0.7$)$. In addition, the patients' performance on daily activities did not decline with chronic use of oxycodone CR. In the study conducted by Markenson et al, oxycodone CR significantly reduced interference 
caused by pain with various daily activities including general activity, mood, normal work, sleep, walking ability, and enjoyment of life. ${ }^{43}$ The group also assessed pain during a patient's primary activity by using the Patient Generated Index, which is a tool to assess a patient's satisfaction with activities selected by the patient as important to improve. The scores were significantly higher for patients on oxycodone $\mathrm{CR}$ versus placebo at days 30 and $45(P=0.027$ and $P=0.007$, respectively) indicating an improvement in the patients' activities. Overall, patients were satisfied with oxycodone CR. ${ }^{43}$ Overall, patients receiving oxycodone CR experienced a significant improvement in various quality of life parameters including mood, sleep, enjoyment of life, and physical activity.

\section{AEs}

AEs associated with oxycodone CR in Caldwell et al's study were those generally seen with opioids. In addition, the effects of nausea and dry mouth were of lower incidence when compared to patients on immediate release oxycodone. ${ }^{41}$ In a trial of 133 patients, 87 (65.4\%) of 133 patients reported at least one treatment-emergent AE during the study; the most common were known opioid-related side effects. A total of 70 patients $(52.6 \%)$ discontinued study participation prematurely, 39 because of ineffective treatment (significantly more in the placebo group, $P<0.001$ for $20 \mathrm{mg}$ every 12 hours) and 28 because of AEs (predominantly nausea, vomiting, and somnolence in active groups). In the long-term extension, more than $10 \%$ of the population experienced AEs that were related to opioids (constipation, somnolence, nausea, pruritus, nervousness, headache, and insomnia, with five patients experiencing probable drug-related serious AEs that resulted in hospitalization. ${ }^{42}$ In the study conducted by Markenson et al, AEs experienced were those typical of an oral opioid analgesic with a total of $28(55 \%)$ patients in the placebo group and 52 (93\%) of patients in the oxycodone CR group reporting AEs. Three serious AEs were experienced in the oxycodone group with $36 \%$ of the patients discontinued due to AEs. ${ }^{43}$ Overall, AEs experienced by patients in the placebo-controlled trials resembled that of other opioids, which included nausea, vomiting, somnolence, dry mouth, and constipation.

Recently a group led by Saari et al examined the age effects on the pharmacokinetics of oxycodone. ${ }^{44}$ The elimination half-life of intravenous oxycodone showed an agedependent increase from 3.8 hours to 4.6 hours in patients between the age of 25 years and 85 years, respectively, and simulations of repetitive bolus dosing showed a $20 \%$ increase in oxycodone concentration in the elderly. The review did not include a measure of AEs, so the clinical implications of the pharmacokinetic changes are not known, but the study authors suggested that dosing should be reduced and carefully titrated in the elderly in order to avoid excess accumulation of oxycodone and potentially hazardous side effects.

\section{Comparative trials}

\section{Oxymorphone ER versus oxycodone CR}

In a trial of 491 patients, two doses of oxymorphone ER were compared to oxycodone CR and placebo for up to 4 weeks. ${ }^{45}$ Mean pain intensity at study visits from baseline to 3 weeks significantly decreased in the oxymorphone groups (20 mg every 12 hours or $40 \mathrm{mg}$ every 12 hours) while the oxycodone CR (20 mg every 12 hours) trended toward significance. A similar assessment was made when patient diaries were analyzed for pain. Changes in Western Ontario and McMaster University Osteoarthritis Index scores for pain, stiffness, and physical function were statistically improved from baseline to week four in the oxymorphone ER groups, but were not for the oxycodone CR group. A total of 110 (91\%) in the oxymorphone ER $40 \mathrm{mg}$ group, 113 (95\%) in the oxymorphone ER $20 \mathrm{mg}$ group, 110 (88\%) in the oxycodone CR $20 \mathrm{mg}$ group, and $71(57 \%)$ in the placebo group experienced AEs that were considered mild to moderate and were those typically observed with opioid treatment. There was a clinically meaningful greater incidence of nausea $(60 \%-61 \%$ versus $43 \%)$, vomiting $(23 \%-34 \%$ versus $10 \%)$, and pruritus $(19 \%-25 \%$ versus $8 \%)$, and a clinically meaningful lower incidence of headache $(6 \%-11 \%$ versus $18 \%$ ) in the groups taking oxymorphone ER compared with the group taking oxycodone CR. Overall, oxymorphone ER proved to be superior compared to oxycodone CR in regard to pain intensity reduction and the occurrence of side effects.

\section{Hydromorphone ER versus oxycodone CR}

Hale et al analyzed the safety and efficacy of once-a-day hydromorphone ER $(\mathrm{N}=71)$ to oxycodone CR (OxyContin) $(\mathrm{N}=67)$ for up to 6 weeks for patients with moderate to severe osteoarthritic pain. ${ }^{46}$ Mean change in pain intensity on a four-point scale from baseline to end point was similar between hydromorphone and oxycodone $(-0.6$ versus -0.4 , $95 \%$ confidence interval -0.53 to $\infty$ ). In addition, patient global evaluations and their rating on overall effectiveness of treatment were similar. Treatment-emergent AEs occurred in $78.9 \%(56 / 71)$ of patients in the hydromorphone group 
and $79.1 \%(53 / 67)$ of patients in the oxycodone CR group with similar rates of discontinuation in both groups. Other studies have also shown improvement in different sleep outcomes and on the Western Ontario and McMaster University Osteoarthritis Index scale for pain, stiffness, and physical function for both hydromorphone and oxycodone CR. ${ }^{47}$ Overall, both hydromorphone ER and oxycodone CR are adequate for providing pain relief and have a similar risk/ benefit ratio.

\section{Tapentadol ER versus oxycodone CR}

In a study by Afilalo et al, safety and efficacy of ER tapentadol was compared to placebo and oxycodone CR (OxyContin) for up to 12 weeks in 1023 patients. ${ }^{48}$ Patients were titrated for 3 weeks and then maintained for up to 12 weeks. Tapentadol ER significantly reduced average pain intensity from baseline to week twelve, whereas oxycodone $\mathrm{CR}$ did not. Both drugs, however, significantly reduced pain intensity through the 12-week maintenance period. A greater number of patients achieved $>50 \%$ improvement in pain intensity in the tapentadol ER group (32.0\% [110/344]) than in the oxycodone CR group (17.3\% [59/342]; $P=0.023$ versus placebo). Patients in the tapentadol ER and oxycodone CR groups, respectively, experienced at least one treatment-emergent $\mathrm{AE}$ (75.9\% [261/344] versus $87.4 \%$ [299/342]). Incidences of constipation, nausea, vomiting, pruritus, and somnolence were significantly lower in the tapentadol group versus oxycodone.

In another study, the long-term safety and efficacy of oxycodone CR was compared to an ER formulation of tapentadol in patients with chronic pain associated with osteoarthritis of the hip and knee. ${ }^{49} \mathrm{~A}$ total of 894 patients received tapentadol and 223 patients received oxycodone CR for up to 1 year. Overall, $85.7 \%$ (766/894) of patients in the tapentadol ER group and $90.6 \%$ (202/223) of patients in the oxycodone $\mathrm{CR}$ group experienced at least one treatmentemergent AE. The most common treatment-emergent AEs included constipation (38.6\% oxycodone versus $22.6 \%$ tapentadol), nausea ( $33.2 \%$ oxycodone versus $18.1 \%$ tapentadol), dizziness (19.3\% versus $14.8 \%$ ), somnolence, vomiting (13.5\% versus $7 \%)$, headache, fatigue, and pruritus (10.3\% versus 5.4\%). Serious treatment-emergent AEs were low with $4.0 \%$ in the oxycodone group versus $5.5 \%$ in the tapentadol group. Pain intensity scores changed from 7.6 to 4.4 in the tapentadol ER group and 7.6 to 4.5 in the oxycodone CR groups from the start of study to final endpoint. For both tapentadol ER and oxycodone CR, respectively, ratings on the global assessment of study medication of "excellent," "very good," or "good" were reported by the majority of patients $(75.1 \%$ [616/820] and $72.3 \%$ [128/177]) and investigators $(77.3 \%$ [635/821] and $72.3 \%$ [128/177]) at the end of treatment.

Both tapentadol and oxycodone were effective at reducing pain intensity in both studies, but tapentadol presented a better benefit/risk profile. This conclusion was also made after a pooled analysis of three phase III studies comparing tapentadol ER to oxycodone CR in patients with osteoarthritis and chronic low back pain. ${ }^{50}$

Overall, oxycodone $\mathrm{CR}$ was not superior in effectiveness or safety when compared to oxymorphone, hydromorphone, or tapentadol (Table 1). Pain reduction was similar in the hydromorphone and tapentadol studies, but slightly poorer when compared to oxymorphone. Side effects were also similar for all groups, but tapentadol showed a better side effect profile versus oxycodone $\mathrm{CR}$.

\section{Open label trials}

In a recent study by Friedmann et al, long-term safety and efficacy was assessed for oxycodone ER $\left(\operatorname{Remoxy}^{\circledR}\right)$ in patients with osteoarthritis of the knee and hip and low back pain. ${ }^{51}$ Throughout a 12 -month period, 823 patients received one or more doses of oxycodone ER. One or more AEs were experienced by 678 patients ( $82 \%$ ), with the most common side effects related to opioids (constipation, nausea, and somnolence), 173 patients (21\%) discontinued treatment, 133 patients $(16 \%)$ decreased drug dose, and 80 patients (10\%) interrupted taking the study drug because of AEs. A total of 55 patients experienced a serious AE, with five being considered related to the study drug. Mean pain intensity scores decreased significantly from baseline (6.4 to 4.5; $P<0.001)$. At month twelve, quality of analgesia and global assessment of study drugs were rated positively (good, very good, or excellent) by $64 \%$ and $61 \%$ of patients, respectively. The authors concluded that oxycodone ER is safe, well tolerated, and a viable option for treating chronic pain related to osteoarthritis and low back pain.

\section{Discussion}

The American College of Rheumatology guidelines for the treatment of osteoarthritis recommend a variety of nonpharmacologic interventions as the cornerstone of therapy. Pain management is most effective when combined with nonpharmacologic strategies. Patients with severe pain who do not respond to, or cannot tolerate, other analgesics may be considered for more potent opioid therapy. ${ }^{52}$ Chronic opioid therapy may be effective therapy for carefully selected and monitored patients with chronic noncancer pain. ${ }^{53}$ 
Table I Studies assessing safety and efficacy of oxycodone controlled release in patients with osteoarthritis

\begin{tabular}{|c|c|c|c|c|c|c|c|}
\hline Year & Author & $\begin{array}{l}\text { Duration } \\
\text { (months) }\end{array}$ & $\mathbf{N}$ & Trial & $\begin{array}{l}\text { Other } \\
\text { analgesics } \\
\text { allowed }\end{array}$ & Dose & Pain \\
\hline \multicolumn{8}{|c|}{ Placebo-controlled trials } \\
\hline 2000 & Roth et al ${ }^{42}$ & 12 & 133 & $\mathrm{R}, \mathrm{DB}$ & Yes & $\begin{array}{l}10 \text { mg every } \\
12 \text { hours, } \\
20 \text { mg every } \\
12 \text { hours }\end{array}$ & $\begin{array}{l}\text { Oxycodone } C R \text { group } \\
\text { Daily mean pain intensity } \downarrow \text { by } \geq 20 \% \\
\text { at weeks one and two (four-point scale) }\end{array}$ \\
\hline 2005 & $\begin{array}{l}\text { Markenson } \\
\text { et } \mathrm{al}^{43}\end{array}$ & 3 & 170 & $\mathrm{R}, \mathrm{DB}$ & Yes & $\begin{array}{l}10 \text { mg every } \\
12 \text { hours }\end{array}$ & $\begin{array}{l}\text { Oxycodone versus placebo } \\
\text { BPI pain intensity } \downarrow \text { ( } 5.1 \pm 0.3 \text { versus } \\
6.0 \pm 0.3 ; P=0.042 \text { ) } \\
\text { WOMAC scores for pain, stiffness, and } \\
\text { physical function significantly } \downarrow \text { at } 30 \text { and } \\
60 \text { days. } 38 \% \text { versus } 17.6 \% \text { achieved } 30 \% \downarrow \text { in } \\
\text { pain. } 20 \% \text { versus } 5.9 \% \text { achieved } 50 \% \downarrow \text { in pain }\end{array}$ \\
\hline \multicolumn{8}{|c|}{ Oxymorphone versus oxycodone } \\
\hline 2005 & Matsumoto 45 & 1 & 491 & $\mathrm{R}, \mathrm{DB}, \mathrm{A}$ & No & $\begin{array}{l}\text { Oxymorphone ER } \\
20 \text { mg every } \\
12 \text { hours, } \\
40 \text { mg every } \\
12 \text { hours } \\
\text { Oxycodone CR } \\
20 \text { mg every } \\
12 \text { hours }\end{array}$ & $\begin{array}{l}\text { API VAS } \downarrow \text { significantly for oxymorphone } \\
\text { groups at } 3 \text { weeks and } 4 \text { weeks, trended } \\
\text { towards significance for oxycodone group } \\
\text { WOMAC scores for pain, physical function, } \\
\text { and stiffness significantly } \downarrow \text { in oxymorphone } \\
\text { groups versus placebo, no significant change } \\
\text { in oxycodone versus placebo }\end{array}$ \\
\hline \multicolumn{8}{|c|}{ Hydromorphone versus oxycodone } \\
\hline 2007 & Hale et $\mathrm{al}^{46}$ & 1.5 & 138 & $\mathrm{R}, \mathrm{OL}$ & $\begin{array}{l}\text { Not } \\
\text { described }\end{array}$ & $\begin{array}{l}\text { Oxycodone } \\
\text { Initial dose } 10 \mathrm{mg} \\
\text { every } 12 \text { hours } \uparrow \\
\text { to } 80 \mathrm{mg} \text { every } \\
12 \text { hours } \\
\text { Hydromorphone } \\
8 \mathrm{mg} \text { every } 24 \text { hours } \\
\text { up to } 64 \mathrm{mg} \text { every } \\
24 \text { hours }\end{array}$ & $\begin{array}{l}\text { Hydromorphone versus oxycodone } \\
\text { Mean pain relief score of } 2.3 \text { versus } 2.3 \\
(95 \% \mathrm{Cl}-0.30 \text { to } \infty) \\
\text { Mean time to the third day of moderate } \\
\text { to complete pain relief was } 6.2 \text { versus } 5.5 \text { days } \\
(95 \% \mathrm{Cl}-0.3 \mathrm{I} \text { to } \infty) \text {. } \\
\text { Mean (SD) changes in pain intensity was } \\
-0.6(0.80) \text { versus }-0.4(\mathrm{I} .15) \\
\text { Mean changes in WOMAC pain scale was }-2.1 \\
(1.96) \text { versus }-2.0(2.03)\end{array}$ \\
\hline \multicolumn{8}{|c|}{ Tapentadol versus oxycodone } \\
\hline 2010 & Afilalo et $\mathrm{al}^{48}$ & 3 & 1030 & $\begin{array}{l}\text { R, DB, A, } \\
\text { Placebo }\end{array}$ & No & $\begin{array}{l}\text { Tapentadol ER } \\
\text { twice daily } \\
(100-250 \mathrm{mg}) \\
\text { Oxycodone CR } \\
\text { twice daily } \\
(20-50 \mathrm{mg})\end{array}$ & $\begin{array}{l}\text { Tapentadol ER } \\
\text { Significantly } \downarrow \text { average pain intensity } \\
\text { versus placebo } \\
\text { Mean difference of }-0.7 \text { ( } 95 \% \mathrm{Cl}-1.04 \\
\text { to }-0.33 \text { ) and throughout the maintenance } \\
\text { period ( }-0.7 \text { [ }-1.00 \text { to }-0.33] \text { ). } \\
\text { Oxycodone CR } \\
\text { Significantly } \downarrow \text { average pain intensity from } \\
\text { baseline throughout the maintenance period } \\
\text { versus placebo mean difference }-0.3 \\
\text { [95\% Cl }-0.67 \text { to }-0.00] \text {, but not at week twelve } \\
\text { Tapentadol ER versus placebo } \\
\text { Significantly } \uparrow \text { percentage of patients achieving } \\
50 \% \text { reduction in average pain intensity } \\
\text { (32.0\% [ I I0/344] versus } 24.3 \% \text { [ } 82 / 337] \text {; } \\
P=0.027 \text { ). } \\
\text { Oxycodone CR versus placebo } \\
\text { Percentage of patients achieving 50\% reduction } \\
\text { in average pain intensity ( } 17.3 \% \text { [59/342] } \\
\text { versus } 24.3 \% \text { [82/337]; } P=0.023 \text { ) }\end{array}$ \\
\hline
\end{tabular}


Oxycodone CR group

Significantly improved mood, sleep, enjoyment of life, walking ability, general activity,

normal work, relationships with others

Oxycodone versus placebo

BPI interference of pain scales for general activity, mood, walking ability, normal work, relations with people, sleep, and enjoyment of life significantly $\downarrow$

Oxymorphone ER superior to placebo for Patient Global Assessment, oxycodone CR was not. Oxymorphone improved quality of life with physical and mental aspects, oxycodone improved only mental. Both improved sleep

Patient/investigator global evaluations similar. Overall effectiveness of treatment rated as good, very good, or excellent by $67.2 \%$ (43/64) of patients in the OROS ${ }^{\circledR}$ hydromorphone group and $66.7 \%$ (40/60) of patients in the ER oxycodone group. Medical Outcomes Study Sleep Problems Index I indicated significantly less sleep disruption and daytime somnolence in hydromorphone versus oxycodone

Tapentadol ER versus placebo Statistically significant improvement on the SF-36 "physical functioning," "role-physical," "bodily pain," and "physical component summary" subscale scores. Significant differences in favor of placebo versus oxycodone CR for changes from baseline to end of treatment in the SF-36 "role-physical," "vitality," "social functioning," "role-emotional," "mental health," and "mental component summary" subscale scores
Oxycodone $C R$ group

IET $=17(19.3 \%)$

$\mathrm{AEs}=26(29.5 \%)$

Placebo

$\mathrm{IET}=22$

$\mathrm{AE}=2$

Oxycodone CR Group

$\mathrm{IET}=9(16 \%)$

$\mathrm{AEs}=20(36 \%)$

Placebo

$\mathrm{IET}=34(67 \%)$

$\mathrm{AE}=2(4 \%)$

Oxymorphone

IET $=$ I 4 (5.8\%)

$\mathrm{AEs}=103(43 \%)$

Oxycodone

$\mathrm{IET}=\mathrm{I} 3(10.4 \%)$

$\mathrm{AEs}=3 \mathrm{I}(24.8 \%)$

Placebo

$\mathrm{IET}=34(27.4 \%)$

$\mathrm{AEs}=6(4.8 \%)$

Hydromorphone

$\mathrm{IET}=\mathrm{I} / 28$

AEs $=25 / 28$

Oxycodone

IET $=3 / 27$

$\mathrm{AEs}=22 / 27$
AEs were typical opioid related.

Top three AEs: constipation, nausea, somnolence

AEs were typical opioid related.

Top three AEs: constipation, nausea, somnolence
At least one AE was reported for 404 patients (83\%) who received study medication: $91 \%$ in the oxymorphone ER $40 \mathrm{mg}$ group $95 \%$ in the oxymorphone ER $20 \mathrm{mg}$ group $88 \%$ in the oxycodone CR $20 \mathrm{mg}$ group $57 \%$ in the placebo group. Frequent AEs typical of opioids

Treatment-emergent AEs $78.9 \%$ versus $79.1 \%$

AEs typical of opioid treatment
Tapentadol

IET $=15 / 163$

$\mathrm{AEs}=61 / 163$

Oxycodone

$\mathrm{IET}=7 / 224$

$A E s=140 / 224$
Treatment-emergent AEs

Placebo: 6I.1\% (206/337)

Tapentadol ER: 75.9\% (26I/344)

Oxycodone CR: 87.4\% (299/342)

Frequent AEs typical of opioid treatment.

Constipation and nausea/vomiting significantly $\downarrow$ in tapentadol. ER group versus oxycodone CR 
Table I (Continued)

\begin{tabular}{|c|c|c|c|c|c|c|c|}
\hline Year & Author & $\begin{array}{l}\text { Duration } \\
\text { (months) }\end{array}$ & $\mathbf{N}$ & Trial & $\begin{array}{l}\text { Other } \\
\text { analgesics } \\
\text { allowed }\end{array}$ & Dose & Pain \\
\hline \multirow[t]{2}{*}{2010} & Wild et $\mathrm{al}^{49}$ & 12 & 1117 & $\mathrm{R}, \mathrm{OL}, \mathrm{A}$ & No & $\begin{array}{l}\text { Tapentadol ER } \\
\text { twice daily } \\
(100-250 \mathrm{mg})\end{array}$ & $\begin{array}{l}\text { Tapentadol versus oxycodone } \\
\text { Baseline mean }(\mathrm{SE}) \text { pain intensity scores } 7.6 \\
(0.05) \text { versus } 7.6(0 . \mathrm{II})\end{array}$ \\
\hline & & & & & & $\begin{array}{l}\text { Oxycodone CR } \\
\text { twice daily } \\
(20-50 \mathrm{mg})\end{array}$ & $\begin{array}{l}\text { At endpoint, mean pain intensity (SE) } \downarrow \text { to } 4.4 \\
(0.09) \text { versus } 4.5(0.17)\end{array}$ \\
\hline
\end{tabular}

\section{Open label trials}

2011 Friedman ${ }^{5}$

12

$823 \quad \mathrm{OL}$
Yes
5-80 mg every
12 hours

Pain intensity scores significantly $\downarrow$ compared

to baseline $(P \leq 0.00 \mathrm{I})$

Mean (SD) change in pain intensity scores

at month six was $-2.0(2.6)$ and at month

twelve was $-2.1(2.7 ; P \leq 0.00 \mathrm{I})$

Abbreviations: A, active controlled; AE, adverse event; API, Arthritis Pain Inventory; BPI, Brief Pain Inventory; Cl, confidence interval; DB, double-blind; IET, ineffective treatment; OL, open label; R, randomized; SD, standard deviation; SE, standard error; VAS, Visual Analog Scale; WOMAC, Western Ontario and McMaster University Osteoarthritis Index.

Caring for patients struggling with moderate to severe chronic osteoarthritis pain requires the clinician to carefully weigh the benefits and disadvantages of long-term opioid therapy and to select the appropriate opioid product. Pharmacokinetic conclusions that intravenous oxycodone $\mathrm{CR}$ has a significantly longer half-life in older versus younger patients ( 3.8 hours in 25 year olds and 4.6 hours in 85 year olds) is not surprising but concerning, although one cannot draw conclusions about the use of oral oxycodone from this study. Age-dependent pharmacokinetic differences have been observed and mean that oxycodone, and indeed other opioids, must be used prudently and under close clinical supervision in the elderly, that is, the population most likely to suffer from osteoarthritis pain. Oxycodone CR clearly offered significant pain relief when compared to placebo, but that relief was associated with the typical side effects of opioid agents: constipation, somnolence, pruritus, nausea, nervousness, headache, and insomnia. Such side effects can often be successfully managed, but it is important to recognize that in these studies, some patients experienced possibly drug-related serious AEs.

Several of these studies showed durable analgesia with oxycodone $\mathrm{CR}$ and patients reported being satisfied with the treatment, which reportedly did not adversely impact their ability to carry out the activities of everyday living. Quality of life improvements along with better sleep and mood were reported with oxycodone CR. These are important findings, in that patients with moderate to severe osteoarthritis pain require long-term, even lifelong, pain management.

When oxycodone $\mathrm{CR}$ was compared to specific other analgesics (oxycodone ER, oxymorphone, hydromorphone, and tapentadol), oxycodone CR was not found to be significantly safer or more effective. Oxymorphone offered greater pain relief; tapentadol patients had fewer side effects. However, the current review mixed studies with different objectives and designs. It is reasonable to conclude that oxycodone CR offered similar, but not superior, safety and efficacy compared to the aforementioned agents.

The literature reviewed supports the fact that oxycodone $\mathrm{CR}$ is safe and effective and significantly reduces moderate to severe chronic pain in osteoarthritis patients with the expected side effects associated with other opioid agents. Comparative studies indicate that it is similar to other products, which means that clinicians should consider the individual needs of each patient when selecting a long-term opioid to manage moderate to severe chronic pain associated with osteoarthritis. Physicians need to consider the risks and benefits of long-acting opioids in their osteoarthritis patients. Risk-benefit considerations include, but are not limited to, variability of patient response,${ }^{54}$ potential drugdrug interactions, ${ }^{55}$ potential side effects, opioid rotation, and 


\begin{tabular}{|c|c|c|}
\hline Quality of life indicators & Discontinuations & AEs \\
\hline $\begin{array}{l}\text { Tapentadol versus oxycodone } \\
\text { Global assessment of excellent, very good, or good } \\
\text { were reported by patients }(75.1 \% \text { versus } 72.3 \%) \\
\text { and investigators ( } 77.3 \% \text { versus } 72.3 \%)\end{array}$ & $\begin{array}{l}\text { Tapentadol } \\
\text { IET }=72(8.1 \%) \\
\text { AEs }=203(22.7 \%) \\
\text { Oxycodone } \\
\text { IET }=7(3.1 \%) \\
\text { AEs }=82(36.8 \%)\end{array}$ & $\begin{array}{l}85.7 \%(766 / 894) \text { versus } 90.6 \%(202 / 223) \\
\text { experienced at least one treatment-emergent AE. } \\
\text { Frequent AEs typical of opioid treatment } \\
\text { Incidences (tapentadol versus oxycodone) } \\
\text { Constipation: } \\
22.6 \% \text { versus } 38.6 \% \\
\text { Nausea: } \\
18.1 \% \text { versus } 33.2 \% \\
\text { Vomiting: } \\
7.0 \% \text { versus } 13.5 \% \\
\text { Pruritus: } \\
5.4 \% \text { versus } 10.3 \% \\
\text { Dizziness: } \\
14.8 \% \text { versus } 19.3 \%\end{array}$ \\
\hline $\begin{array}{l}\text { Quality of analgesia was rated as good, very good, } \\
\text { or excellent at months six and twelve by } \\
61 \% \text { and } 64 \% \text { of patients. } \\
\text { Study drug was rated as good, very good, } \\
\text { or excellent by } 60 \% \text { and } 61 \% \text { of patients }\end{array}$ & $\begin{array}{l}\mathrm{IET}=15 / 443 \\
\mathrm{AEs}=173 / 443\end{array}$ & $\begin{array}{l}678 / 823(82 \%) \text { experienced at least one } \mathrm{AE} \\
\text { Frequent } \mathrm{AEs} \text { typical of opioid treatment }\end{array}$ \\
\hline
\end{tabular}

possibility of abuse, misuse, or addiction. ${ }^{53}$ The following points should be considered when identifying the appropriate patient for oxycodone CR therapy: (a) have they tried nonpharmacologic interventions?; (b) have they failed to respond or cannot tolerate nonopioid analgesics?; and (c) are immediate release opioids dosed every 4-6 hours aroundthe-clock being considered or might they benefit from every 12 hours dosing? $?^{56}$ If the patient is an appropriate candidate for long-acting oxycodone therapy, then the next step is to assess his or her pain, the historical level of pain, and any history of abuse. Therapy should be targeted at achieving optimal analgesia at the lowest effective dose.

\section{Limitations}

This is a literature review and not a meta-analysis. The literature search relied on keywords being present in the article title and no attempt was made to assess the quality of the study. This might result in overemphasizing lower-quality studies or underemphasizing higher-quality ones. The eleven studies identified included placebo-controlled, comparative, safety, and pharmacokinetic studies which have, by definition, different objectives. Thus, there is a distinct heterogeneity of results with no attempt made to weight studies by goals or design. Further, no attempts were made to stratify the findings based on studies involving knee osteoarthritis versus hip osteoarthritis or other types of osteoarthritis. As a result, the paper should be viewed as offering a high-level overview of oxycodone CR products in the treatment of osteoarthritis pain rather than providing specific clinical insights.

\section{Conclusion}

Clinical studies have demonstrated reasonable efficacy, safety, and tolerability of oxycodone $\mathrm{CR}$ when used to manage moderate to severe chronic osteoarthritis pain. The most common AEs are gastrointestinal and central nervous system related. These side effects might be more pronounced in elderly and debilitated patients. All patients need to be regularly assessed for the potential of abuse, misuse, and addiction, as well as the need for continued opioid therapy. Finally, it is important to incorporate a multimodal pain management regimen that includes nonpharmacologic and pharmacologic therapies when treating chronic osteoarthritis-related pain.

\section{Disclosure}

The authors report no conflicts of interest in this work.

\section{References}

1. Corti MC, Rigon C. Epidemiology of osteoarthritis: prevalence, risk factors and functional impact. Aging Clin Exp Res. 2003;15(5):359-363.

2. Zhang Y, Jordan JM. Epidemiology of osteoarthritis. Clin Geriatr Med. 2010;26(3):355-369. 
3. Breedveld FC. Osteoarthritis - the impact of a serious disease. Rheumatology (Oxford). 2004;43 Suppl 1:i4-i8.

4. Lawrence RC, Felson DT, Helmick CG, et al. Estimates of the prevalence of arthritis and other rheumatic conditions in the United States. Part II. Arthritis Rheum. 2008;58(1):26-35.

5. Abramson SB, Attur M. Developments in the scientific understanding of osteoarthritis. Arthritis Res Ther. 2009;11(3):227.

6. Nuki G. Osteoarthritis: a problem of joint failure. $Z$ Rheumatol. 1999;58(3):142-147.

7. Loeser RF. Aging and osteoarthritis. Curr Opin Rheumatol. 2011;23(5): 492-496.

8. McDonough CM, Jette AM. The contribution of osteoarthritis to functional limitations and disability. Clin Geriatr Med. 2010;26(3):387-399.

9. Hawker GA, Stewart L, French MR, et al. Understanding the pain experience in hip and knee osteoarthritis - an OARSI/OMERACT initiative. Osteoarthritis Cartilage. 2008;16(4):415-422.

10. American College of Rheumatology Subcommittee on Osteoarthritis Guidelines. Recommendations for the medical management of osteoarthritis of the hip and knee: 2000 update. Arthritis Rheum. 2000;43(9):1905-1915.

11. Seed SM, Dunican KC, Lynch AM. Treatment options for osteoarthritis: considerations for older adults. Hosp Pract (Minneap). 2011;39(1):62-73.

12. Manek NJ, Lane NE. Osteoarthritis: current concepts in diagnosis and management. Am Fam Physician. 2000;61(6):1795-1804.

13. Zhang W, Moskowitz RW, Nuki G, et al. OARSI recommendations for the management of hip and knee osteoarthritis, part I: critical appraisal of existing treatment guidelines and systematic review of current research evidence. Osteoarthritis Cartilage. 2007;15(9):981-1000.

14. Gibofsky A, Barkin RL. Chronic pain of osteoarthritis: considerations for selecting an extended-release opioid analgesic. Am J Ther. 2008;15(3):241-255.

15. Case JP, Baliunas AJ, Block JA. Lack of efficacy of acetaminophen in treating symptomatic knee osteoarthritis: a randomized, double-blind, placebo-controlled comparison trial with diclofenac sodium. Arch Intern Med. 2003;163(2):169-178.

16. Towheed TE, Maxwell L, Judd MG, Catton M, Hochberg MC, Wells G. Acetaminophen for osteoarthritis. Cochrane Database Syst Rev. 2006;1:CD004257.

17. Zhang W, Jones A, Doherty M. Does paracetamol (acetaminophen) reduce the pain of osteoarthritis? A meta-analysis of randomised controlled trials. Ann Rheum Dis. 2004;63(8):901-907.

18. Bjordal JM, Ljunggren AE, Klovning A, Slordal L. Non-steroidal anti-inflammatory drugs, including cyclo-oxygenase-2 inhibitors, in osteoarthritic knee pain: meta-analysis of randomised placebo controlled trials. BMJ. 2004;329(7478):1317.

19. Ong CKS, Lirk P, Tan CH, Seymour RA. An evidence-based update on nonsteroidal anti-inflammatory drugs. Clin Med Res. 2007;5(1):19-34.

20. Smalley WE, Ray WA, Daugherty JR, Griffin MR. Nonsteroidal antiinflammatory drugs and the incidence of hospitalizations for peptic ulcer disease in elderly persons. Am J Epidemiol. 1995;141(6):539-545.

21. Blantz RC. Acetaminophen: acute and chronic effects on renal function. Am J Kidney Dis. 1996;28(1 Suppl 1):S3-S6.

22. Brandt KD. The role of analgesics in the management of osteoarthritis pain. Am J Ther. 2000;7(2):75-90.

23. Katz WA. Use of nonopioid analgesics and adjunctive agents in the management of pain in rheumatic diseases. Curr Opin Rheumatol. 2002;14(1):63-71.

24. Mamdani M, Rochon PA, Juurlink DN, et al. Observational study of upper gastrointestinal haemorrhage in elderly patients given selective cyclo-oxygenase-2 inhibitors or conventional non-steroidal antiinflammatory drugs. BMJ. 2002;325(7365):624.

25. Taylor R Jr, Pergolizzi JV Jr, Raffa RB. Acetaminophen (paracetamol): properties, clinical uses, and adverse effects. In: Javaherian A, Latifpour P, editors. Acetaminophen: Properties, Clinical Uses and Adverse Effects. Hauppauge, NY: Nova Science Publishers Inc; 2012. In press.
26. McHughes M, Lipman AG. Managing osteoarthritis pain when your patient fails simple analgesics and NSAIDs and is not a candidate for surgery. Curr Rheumatol Rep. 2006;8(1):22-29.

27. Howes F, Buchbinder R, Winzenberg TB. Opioids for osteoarthritis? Weighing benefits and risks: a Cochrane Musculoskeletal Group review. J Fam Pract. 2011;60(4):206-212.

28. Pergolizzi J, Boger RH, Budd K, et al. Opioids and the management of chronic severe pain in the elderly: consensus statement of an International Expert Panel with focus on the six clinically most often used World Health Organization Step III opioids (buprenorphine, fentanyl, hydromorphone, methadone, morphine, oxycodone). Pain Pract. 2008;8(4):287-313.

29. American Geriatrics Society Panel on the Pharmacological Management of Persistent Pain in Older Persons. Pharmacological management of persistent pain in older persons. Pain Med. 2009;10(6): $1062-1083$.

30. Nicholson B. Responsible prescribing of opioids for the management of chronic pain. Drugs. 2003;63(1):17-32.

31. Hariharan J, Lamb GC, Neuner JM. Long-term opioid contract use for chronic pain management in primary care practice. A five year experience. J Gen Intern Med. 2007;22(4):485-490.

32. McCarberg BH, Barkin RL. Long-acting opioids for chronic pain: pharmacotherapeutic opportunities to enhance compliance, quality of life, and analgesia. Am J Ther. 2001;8(3):181-186.

33. Sloan $\mathrm{P}, \mathrm{Babul} \mathrm{N}$. Extended-release opioids for the management of chronic non-malignant pain. Expert Opin Drug Deliv. 2006;3(4):489-497.

34. Heiskanen T, Kalso E. Controlled-release oxycodone and morphine in cancer related pain. Pain. 1997;73(1):37-45.

35. Bruera E, Belzile M, Pituskin E, et al. Randomized, double-blind, cross-over trial comparing safety and efficacy of oral controlled-release oxycodone with controlled-release morphine in patients with cancer pain. J Clin Oncol. 1998;16(10):3222-3229.

36. Mucci-LoRusso P, Berman BS, Silberstein PT, et al. Controlled-release oxycodone compared with controlled-release morphine in the treatment of cancer pain: a randomized, double-blind, parallel-group study. Eur J Pain. 1998;2(3):239-249.

37. Stambaugh JE, Reder RF, Stambaugh MD, Stambaugh H, Davis M. Double-blind, randomized comparison of the analgesic and pharmacokinetic profiles of controlled- and immediate-release oral oxycodone in cancer pain patients. J Clin Pharmacol. 2001;41(5):500-506.

38. Koizumi W, Toma H, Watanabe K, et al. Efficacy and tolerability of cancer pain management with controlled-release oxycodone tablets in opioid-naive cancer pain patients, starting with $5 \mathrm{mg}$ tablets. Jpn J Clin Oncol. 2004;34(10):608-614.

39. Nicholson B, Ross E, Sasaki J, Weil A. Randomized trial comparing polymer-coated extended-release morphine sulfate to controlled-release oxycodone $\mathrm{HCl}$ in moderate to severe nonmalignant pain. Curr Med Res Opin. 2006;22(8):1503-1514.

40. Furlan AD, Sandoval JA, Mailis-Gagnon A, Tunks E. Opioids for chronic noncancer pain: a meta-analysis of effectiveness and side effects. CMAJ. 2006;174(11):1589-1594.

41. Caldwell JR, Hale ME, Boyd RE, et al. Treatment of osteoarthritis pain with controlled release oxycodone or fixed combination oxycodone plus acetaminophen added to nonsteroidal antiinflammatory drugs: a double blind, randomized, multicenter, placebo controlled trial. J Rheumatol. 1999;26(4):862-869.

42. Roth SH, Fleischmann RM, Burch FX, et al. Around-the-clock, controlled-release oxycodone therapy for osteoarthritis-related pain: placebo-controlled trial and long-term evaluation. Arch Intern Med. 2000;160(6):853-860.

43. Markenson JA, Croft J, Zhang PG, Richards P. Treatment of persistent pain associated with osteoarthritis with controlled-release oxycodone tablets in a randomized controlled clinical trial. Clin J Pain. 2005;21(6):524-535.

44. Saari TI, Ihmsen H, Neuvonen PJ, Olkkola KT, Schwilden H. Oxycodone clearance is markedly reduced with advancing age: a population pharmacokinetic study. Br J Anaesth. 2012;108(3):491-498. 
45. Matsumoto AK, Babul N, Ahdieh H. Oxymorphone extended-release tablets relieve moderate to severe pain and improve physical function in osteoarthritis: results of a randomized, double-blind, placebo- and active-controlled phase III trial. Pain Med. 2005;6(5):357-366.

46. Hale M, Tudor IC, Khanna S, Thipphawong J. Efficacy and tolerability of once-daily OROS hydromorphone and twice-daily extended-release oxycodone in patients with chronic, moderate to severe osteoarthritis pain: results of a 6-week, randomized, open-label, noninferiority analysis. Clin Ther. 2007;29(5):874-888.

47. Gajria K, Kosinski M, Schein J, Kavanagh S, Dubois D. Health-related quality-of-life outcomes in patients treated with push-pull OROS hydromorphone versus extended-release oxycodone for chronic hip or knee osteoarthritis pain: a randomized, open-label, parallel-group, multicenter study. Patient. 2008;1(3):223-238.

48. Afilalo M, Etropolski MS, Kuperwasser B, et al. Efficacy and safety of tapentadol extended release compared with oxycodone controlled release for the management of moderate to severe chronic pain related to osteoarthritis of the knee: a randomized, double-blind, placebo- and active-controlled phase III study. Clin Drug Investig. 2010;30(8):489-505

49. Wild JE, Grond S, Kuperwasser B, et al. Long-term safety and tolerability of tapentadol extended release for the management of chronic low back pain or osteoarthritis pain. Pain Pract. 2010;10(5):416-427.
50. Lange B, Kuperwasser B, Okamoto A, et al. Efficacy and safety of tapentadol prolonged release for chronic osteoarthritis pain and low back pain. Adv Ther. 2010;27(6):381-399.

51. Friedmann N, Klutzaritz V, Webster L. Long-term safety of Remoxy ${ }^{\circledR}$ (extended-release oxycodone) in patients with moderate to severe chronic osteoarthritis or low back pain. Pain Med. 2011;12(5):755-760.

52. Chou R, Huffman LH. Nonpharmacologic therapies for acute and chronic low back pain: a review of the evidence for an American Pain Society/American College of Physicians clinical practice guideline. Ann Intern Med. 2007;147(7):492-504.

53. Chou R, Fanciullo GJ, Fine PG, et al. Clinical guidelines for the use of chronic opioid therapy in chronic noncancer pain. J Pain. 2009;10(2):113-130.

54. Pergolizzi JV Jr, Labhsetwar SA, Puenpatom RA, Joo S, Ben-Joseph RH, Summers KH. Prevalence of exposure to potential CYP450 pharmacokinetic drug-drug interactions among patients with chronic low back pain taking opioids. Pain Pract. 2011;11(3):230-239.

55. Galer BS, Coyle N, Pasternak GW, Portenoy RK. Individual variability in the response to different opioids: report of five cases. Pain 1992;49(1):87-91.

56. OxyContin ${ }^{\circledR}$ (oxycodone hydrochloride controlled-release) tablets [package insert.] Stamford, CT: Purdue Pharma LP; 2010.
Journal of Pain Research

\section{Publish your work in this journal}

The Journal of Pain Research is an international, peer-reviewed, open access, online journal that welcomes laboratory and clinical findings in the fields of pain research and the prevention and management of pain. Original research, reviews, symposium reports, hypothesis formation and commentaries are all considered for publication.

\section{Dovepress}

The manuscript management system is completely online and includes a very quick and fair peer-review system, which is all easy to use. Visit http://www.dovepress.com/testimonials.php to read real quotes from published authors. 